\title{
DISCIPLINA DE LIBRAS NA GRADUAÇÃO: O ENSINO DE LIBRAS E SOBRE A LIBRAS.
}

Laís dos Santos di Benedetto ${ }^{1}$, Elisa Tomoe Moriya Schlünzen ${ }^{2}$, Danielle Aparecida do Nascimento dos Santos ${ }^{2,3}$

Universidade Estadual Paulista - UNESP, ${ }^{1}$ Programa de Pós-Graduação em Educação. ${ }^{2}$ Departamento de Educação de Estatística, Presidente Prudente, SP. ${ }^{3}$ Universidade do Oeste Paulista - UNOESTE - Mestrado em Educação, Presidente Prudente, SP. Email: libras.lais@hotmail.com

\section{RESUMO}

Em 2002 a Lei 10.436 foi promulgada no Brasil, reconhecendo a Língua de Brasileira de Sinais (Libras), como a língua oficial das comunidades surdas brasileiras. Até 2002, iniciativas de disseminação da Libras no contexto educacional não eram reconhecidas pela nossa legislação. Em 2005, o Decreto 5.626 estabeleceu um prazo para que as instituições de ensino superior provessem o ensino da Libras nos cursos de licenciatura e fonoaudiologia. A Unesp, em atendimento a uma comissão da Pró-Reitoria de Graduação (Prograd), iniciou em 2013 um projeto piloto que consistia em oferecer uma disciplina de Libras aos diferentes campi da Unesp, na modalidade a distância. Ofertada em cinco edições, a pesquisa descrita neste artigo problematiza a seleção e análise de conteúdos práticos propostos na disciplina. A pesquisa tem natureza qualitativa. Espera-se caracterizar em que medida os conteúdos tem proporcionado um mínimo de comunicação aos estudantes, principalmente em contextos escolares.

Palavras-chave: Língua de sinais, formação de professores, ensino de Libras, disciplina de Libras.

\section{DISCIPLINE OF LIBRAS AT COLLEGE: THE TEACHING OF LIBRAS AND UPON LIBRAS.}

\begin{abstract}
In 2002, Law 10.436 was enacted in Brazil, recognizing the Brazilian Sign Language (Libras), as the official language of Brazilian deaf communities. Until 2002 Libras dissemination initiatives in the educational context were not recognized by our legislation. In 2005, Decree 5.626 established a deadline for the higher education institutions provessem teaching Pounds in undergraduate and speech therapy. Unesp, in response to a commission from the Office of the Vice President for Undergraduate Studies (Prograd), started in 2013 a pilot project was to offer a course of Libras to the different campuses of Unesp, in the distance. Offered in five editions, the research described in this article discusses the selection and analysis of practical content in the proposed discipline. The research is qualitative. It is expected to characterize the extent to which the content has provided minimum communication for students, especially in school environments.
\end{abstract}

Keywords: Sign language, training teachers, teaching libras, libras of discipline. 


\section{INTRODUÇÃO}

Em 2002 a Lei 10.436 foi promulgada no Brasil, reconhecendo a Língua de Brasileira de Sinais (Libras), como a língua oficial das comunidades surdas brasileiras. Esse reconhecimento, entre outros sentidos, afirma a Libras com status de língua, indicando um viés de abordagem bilíngue para a educação de surdos em nosso país. Em conformidade à Lei, em 2005 o Decreto 5.626 estabeleceu um prazo de dez anos para que as instituições de ensino superior provessem, entre outras exigências, o ensino de Libras como disciplina obrigatória nos cursos de licenciatura e fonoaudiologia.

A Universidade Estadual Paulista "Júlio de Mesquita Filho" (Unesp), como uma instituição de ensino superior comprometida com a qualidade da educação em todos os níveis e modalidades, apresentou em 2012, mediante a Pró-Reitoria de Graduação (Prograd), o projeto de implementação da disciplina de Libras na modalidade a distância.

A proposta da disciplina Libras a Distância integrou ações caracterizadas pela Comissão dos Cursos de Licenciatura da Unesp que já vinha discutindo desde 2005 sobre a necessidade de oferecer o ensino de Libras nos cursos de graduação e que vislumbrou, em uma modalidade de educação que, de acordo com os pressupostos de Valente (2003), com o auxílio adequado de especialistas e com o trabalho pedagógico intencional, pode permitir que se atinjam graus de excelência educacionais cada vez maiores, em uma dinâmica mediada por tecnologias.

Para dar corpus à proposta, a Comissão dos Cursos de Licenciatura da Unesp solicitou apoio de especialistas em Educação a Distância (EaD) e em Educação Especial e Ensino de Libras, encontrando em pesquisadores do Núcleo de Educação a Distância (NEaD) da Unesp e do Centro de Promoção para a Inclusão Digital, Escolar e Social (CPIDES), uma equipe que deu início a um projeto piloto, que consistia oferecer uma disciplina de Libras usufruindo da modalidade a distância para o seu desenvolvimento em formato semipresencial.

Após aproximadamente três anos de execução, em 2016 a disciplina está em sua quinta edição e, como todo processo educacional comprometido com os processos de ensino e aprendizagem, tem sido propostas mudanças em termos da dinâmica e dos conteúdos teóricos e práticos da disciplina, visando melhor atender aos estudantes que tem oportunidade de se envolver com a Libras.

Essas mudanças, relacionadas aos conteúdos teóricos e práticos, visam apresentar aos estudantes, conteúdos sobre a Libras e da Libras, explorando as suas especificidades linguísticas, conforme prevê a Lei 10.436/2002.

Dentre os diferentes aspectos presentes na dinâmica da disciplina, para a sua execução em formato semipresencial, é usado um equipamento de alta tecnologia específico para videoconferências, da empresa Cisco. Com o apoio desse equipamento, os conteúdos práticos da disciplina são ministrados por uma intérprete de Libras, com o apoio de uma pessoa surda.

Ao longo das videoconferências, tem se observado que o contato dos estudantes de uma determinada unidade da Unesp, com os estudantes de outras unidades, com a comunicação direta junto a uma pessoa surda permite que as aulas práticas privilegiem o intercâmbio de culturas e conhecimentos que os permitem identificar essas especificidades linguísticas citadas pela legislação.

Com essas premissas, percebeu-se a necessidade de problematizar em que medida a seleção e análise de conteúdos práticos propostos na disciplina tem influência na compreensão dos estudantes sobre a importância da Libras para a sua formação, não somente com um caráter mecanizado, de operacionalização da aprendizagem de sinais, sem uma conexão com as necessidades formativas presentes na convivência com um surdo ou com a compreensão da proposta bilíngue de ensino.

Nesse sentido, o artigo proposto visa explicitar essa problematização de conteúdos de e para o ensino da Libras, no âmbito da disciplina de Libras ofertada na modalidade EaD, na Unesp. 


\section{METODOLOGIA}

Atualmente intitulada como "Libras, Educação Especial e Inclusiva", a disciplina de Libras é vinculada ao NEaD da Unesp e ao CPIDES, cujo cadastro no comitê de ética é 10206912.2.0000.5402.

Entre as suas especificidades, a disciplina tem o diferencial de ser oferecida para as diferentes áreas da licenciatura, e ainda a fonoaudiologia. Nesse sentido, os conteúdos teóricos e práticos propostos exploram diferentes temas, desde a área da Libras, como da Educação Especial e Inclusiva.

Para a operacionalização desse processo, uma equipe multidisciplinar, contendo, coordenadores, professora conteudista, design educacional, webdesign, tutores online, intérprete de libras e um professor surdo, geralmente, convidado para participar da última aula prática, organizam a disciplina, que contém carga horária de 60 horas.

Os conteúdos e atividades da disciplina são implementados na Moodle e disponibilizados aos estudantes pelo portal Edutec. As 60 horas de estudos são desenvolvidas no semestre letivo por meio de textos, videoaulas, slides autoexplicativos, filmes e vídeos. Para as atividades teóricas, utiliza-se de fóruns de discussão e atividades em forma de textos reflexivos.

Já para as atividades práticas, visa-se obter o entendimento da prática da língua e suas especificidades técnicas. Para isso, são propostas atividades on-line em três formatos: videoaulas em que os estudantes assistem uma pessoa sinalizando em Libras por eixos temáticos. Após assistir essas videoaulas, os estudantes realizam atividades em que devem escolher respostas correspondentes em Língua Portuguesa sobre os sinais referentes ao tema foi discorrido.

No segundo formato, os estudantes são convidados ao exercício e à prática, portanto, devem gravar sinais em Libras, a partir de frases em Língua Portuguesa que são solicitadas. Esse segundo formato foi incorporado à dinâmica da disciplina somente em 2015, quando, por meio dos relatórios, a equipe detectou que os estudantes demandavam a necessidade de ter um feedback mais diretivo da equipe em relação à sua aprendizagem sobre a prática da língua.

Além desses dois formatos de atividades práticas, os estudantes contam ainda conta com o desenvolvimento de quatro aulas práticas com duração de quatro horas cada. Essas aulas práticas são realizadas por meio de videoconferências pela sala virtual CISCO, que existe na maioria das unidades da Unesp.

Nessas videoconferências, a intérprete de Libras explora a conversação com os estudantes e, na última aula prática, com a presença de um instrutor surdo, que dialoga com os estudantes em Libras, os mesmos tem a oportunidade de sanar dúvidas sobre a vida escolar e social dos surdos e sua relação com a Libras.

As videoconferências são consideradas como um momento de suma importância para que os estudantes tenham contato com um falante da língua e possam trocar experiências culturais e conhecer novas ideias sobre a escolarização das pessoas surdas, bem como, possíveis relatos desse período.

A partir de 2015 o planejamento e execução dessas videoconferências passaram a ser objeto de pesquisa do projeto de mestrado intitulado atualmente como "Implementação da Disciplina de Libras em EaD na Unesp". Para a coleta, seleção e análise de dados foram usados materiais como o registro dos relatórios da equipe, registro de reuniões entre coordenação, designer educacional, professor conteudista e intérprete de Libras, planos de aula de cada videoconferência e portfólio de registro das webconferências, que é arquivado pela intérprete de Libras no Google Docs, e compartilhado com a equipe. 


\section{RESULTADOS}

Conforme já relatado, uma das grandes preocupações, ao realizar as atividades práticas, bem como as videoconferências, é o nível de fluência dos estudantes, uma vez que pretende-se formar professores que tenham condições mínimas de comunicação com estudantes surdos.

Uma das fontes que permite compreender essa preocupação é a atividade prática em que os estudantes devem enviar vídeos em Libras. Ao analisar esses registros, é possível compreender o nível de fluência na língua de sinais e as possíveis dificuldades vivenciadas pelos estudantes.

Foram analisados aproximadamente 20 vídeos, e a maioria indica que os estudantes têm dificuldade em utilizar as expressões não-manuais, ENM, (expressões da face e corpo) no início da disciplina, porém, ao final da disciplina, quando os estudantes já exploram as ENM nas videoconferências, essas expressões ficam mais corretas dentro do discurso da Libras.

A Imagem 1, abaixo, demonstra um dos estudantes, ao final da disciplina, realizando os sinais corretamente, bem como, os parâmetros que forma morfologicamente os sinais, como configurações de mãos (posições corretas dos dedos), ponto de articulação adequado (lugar em que o sinal é feito) e bom uso do espaço neutro, além dos outros parâmetros como orientação, movimento e as expressões faciais e corporais.

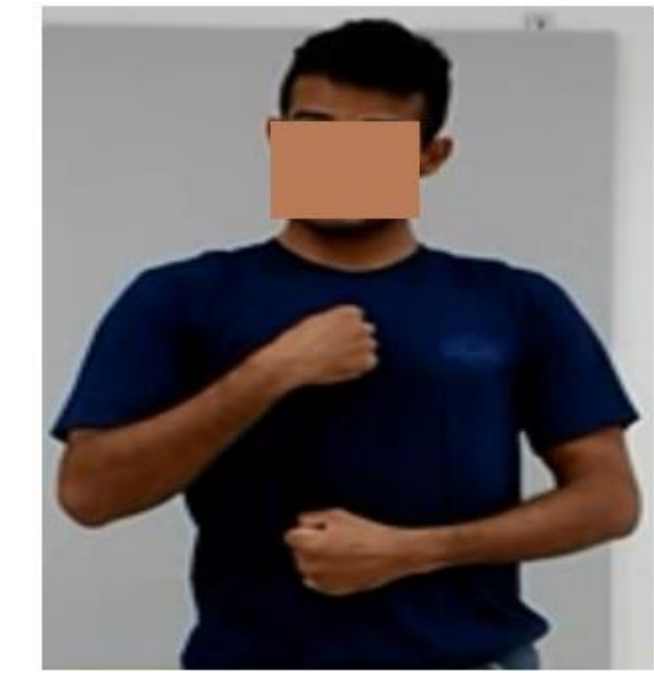

EU

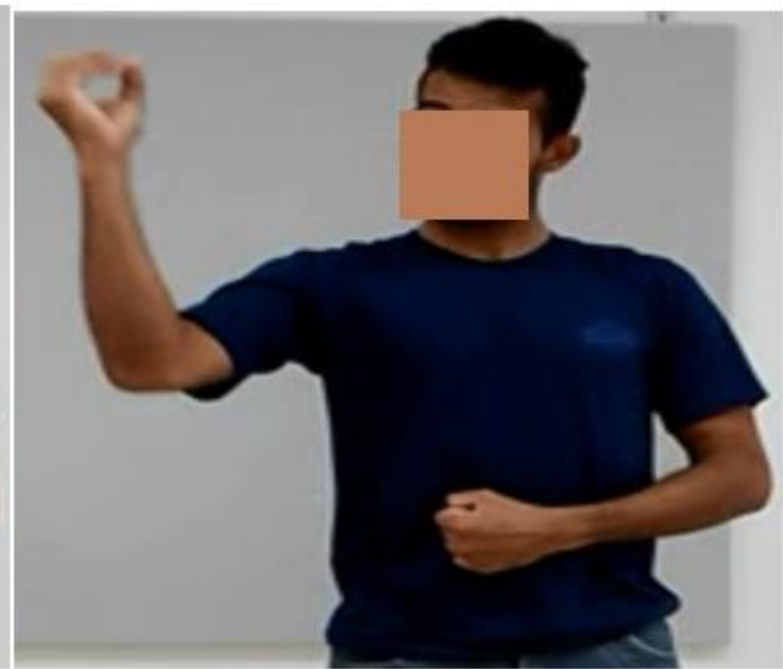

VIAJAR

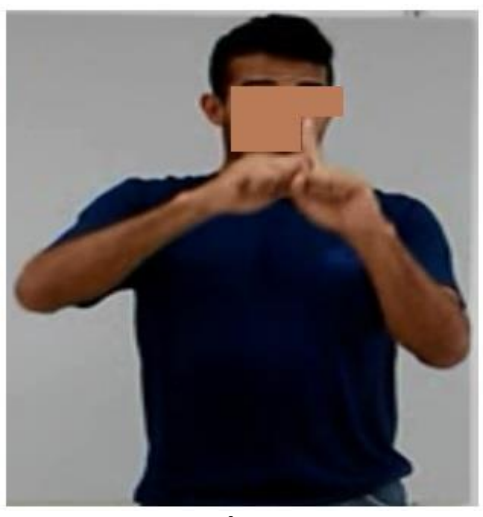

MÊS

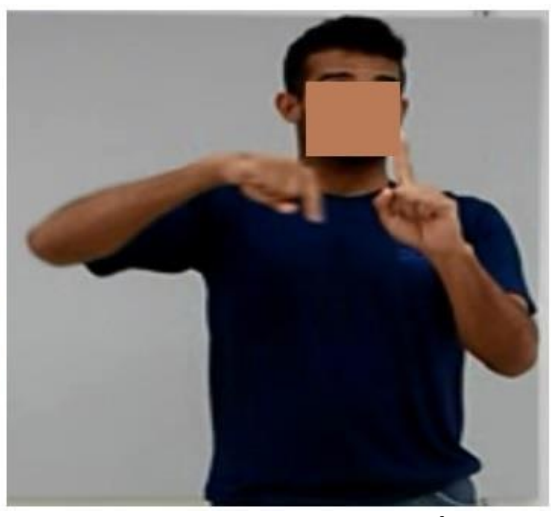

PRÓXIMO

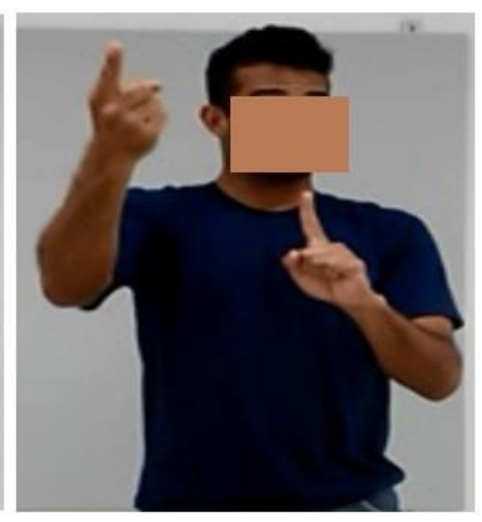




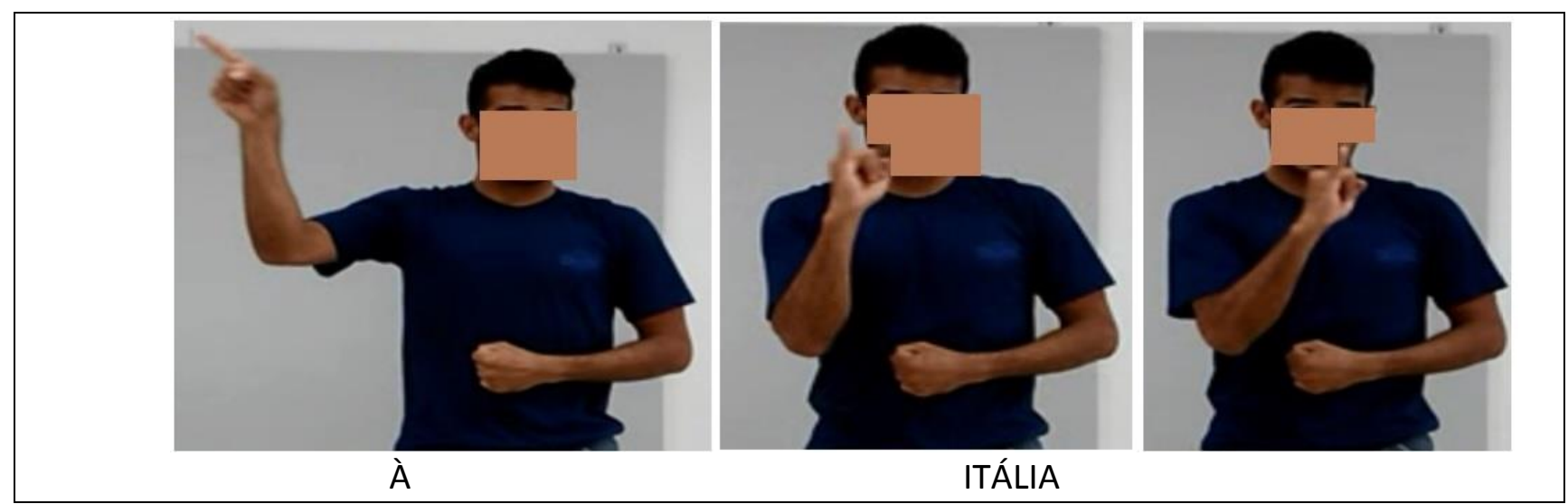

Imagem 1. Esquema explicativo da sinalização da frase apresentada.

Fonte: Elaborada pela autora a partir do print screen das páginas do ambiente Educacional Edutec/Moodle Unesp.

Nesse sentido, é possível observar a postura do estudante e o uso correto do espaço da língua, além das expressões faciais visíveis através das sobrancelhas, testa e movimento da cabeça. Já as expressões corporais, acontecem de acordo com a exigência do sinal, como é ainda mais perceptível nos sinais "viajar" e no termo interpretado como a preposição "à". Esses detalhes são parte da gramática da Libras e seu uso correto, mostra certo domínio na língua.

\section{DISCUSSÃO}

Quando se pensa em ensino de línguas é preciso balancear o que é essencial e esperado aprender naquele período de tempo. Portanto, a análise da abordagem prática de conteúdos na disciplina de Libras tem apontado para o desenvolvimento de estratégias de escolhas de conteúdos que favoreçam o objetivo da disciplina, que é proporcionar o mínimo de comunicação aos estudantes, principalmente em contextos escolares.

Por isso, optou-se pela escolha de conteúdos que abrangesse o cotidiano dos adolescentes surdos, uma vez que a disciplina é oferecida para futuros professores do ensino fundamental II.

Para isso, foram selecionados conteúdos como: alfabeto manual, numerais, pronomes e gramática, saudações, família e pessoas, escolarização, transportes, profissões, localidades, estados, países, clima/natureza, classificadores, higiene pessoal e animais. São assuntos que permitem que os futuros professores tenham vocabulário suficiente para estabelecer o mínimo de diálogo com seus estudantes dentro do ambiente escolar.

O Quadro Europeu Comum de Referência para as línguas (2001) salienta que os estudantes devem aprendem a partir dos seguintes objetivos:

Os enunciados das finalidades e dos objectivos da aprendizagem e do ensino das línguas deveriam ser baseados quer numa apreciação das necessidades dos aprendentes e da sociedade quer nas tarefas, actividades e processos que os aprendentes necessitam de levar a cabo para satisfazer essas necessidades, quer, ainda, nas competências e estratégias que eles necessitam de desenvolver/construir para o conseguir. (CONSELHO DA EUROPA, 2001, p.185)

Dessa forma, entende-se que a disciplina auxilia na formação de professores para conversarem em Libras e que entendam sobre a Libras. Atingindo assim, o objetivo proposto pela disciplina, que não visa formar intérpretes ou professores de Libras, mas formar professores capazes de perguntar e tirar dúvidas de seus estudantes através de sua língua natural, respeitando assim, sua cultura.

Até porque para se tornar um intérprete de língua não basta ter fluência apenas, é preciso dominar as estratégias de tradução e interpretação, bem como os seus diferentes tipos. E para ser 
professor de uma língua é preciso ter domínio de suas especificidades linguísticas e gramaticais, além de dominar metodologias de ensino de línguas. Sobre isso, Campos (2015) afirma que não é possível um curso básico formar um intérprete de Libras, pois esta exige muito estudo e prática, além do que, Bakhtin (1992) afirma que a língua é viva e está em constante transformação.

\section{CONCLUSÃO}

Concluímos que a disciplina de Libras oferecida pela Unesp na modalidade a distância, além de cumprir a legislação, tem permitido atender todas as unidades da Unesp, oferecendo formação de qualidade e trazendo à escola, professores mais instrumentalizados, sabendo minimamente como ajudar seus estudantes surdos a se realizarem na escolarização, como deve ser.

A análise dos materiais presentes nos vídeos enviados pelos estudantes, bem como das videoconferências, demonstra que o ensino de Libras pode proporcionar o desenvolvimento de competências linguísticas mínimas, gerando maior segurança ao estudante surdo, além de levar esses futuros professores a ter consciência da importância de estabelecer uma parceria com o intérprete de Libras, figura que puderam conhecer durante a disciplina.

As discussões da disciplina, principalmente nas videoconferências, embasam os estudantes sobre qual o papel de cada profissional, o professor, o intérprete de Libras e o estudante surdo, e esse esclarecimento já pode dar oportunidade à escolarização dos estudantes surdos em uma perspectiva bilíngue.

\section{REFERÊNCIAS}

BAKHTIN, M. Marxismo e Filosofia da Linguagem. São Paulo: HUCITEC, 1992.

CAMPOS, Mariana de Lima Isaac Leandro. Introdução a Libras - Língua Brasileira de Sinais. Disciplina Desenvolvimento e Aprendizagem da Língua Brasileira de Sinais - Redefor. São Paulo: Nead/Unesp, 2015.

Conselho da Europa (2001). Quadro europeu comum de referência para as línguas. Aprendizagem, ensino avaliação. Porto: Edições Asa.

Decreto 5.626/2005 de 22 de dezembro de 2005

<http://www.planalto.gov.br/ccivil_03/_ato2004-2006/2005/decreto/d5626.htm> em 20/09/2014.

Lei 10.436/2002 de 24 de abril de 2002

<http://www.planalto.gov.br/ccivil_03/LEIS/2002/L10436.htm> em 20/09/2014. 